\title{
Reducing sickness absence in occupational settings
}

Jussi Vahtera and Mika Kivimäki

Occup. Environ. Med. 2008;65;219-220

doi:10.1136/oem.2007.036061

Updated information and services can be found at:

http://oem.bmj.com/cgi/content/full/65/4/219

References

Rapid responses

Email alerting service

\section{These include:}

This article cites 8 articles, 5 of which can be accessed free at: http://oem.bmj.com/cgi/content/full/65/4/219\#BIBL

You can respond to this article at:

http://oem.bmj.com/cgi/eletter-submit/65/4/219

Receive free email alerts when new articles cite this article - sign up in the box at the top right corner of the article

Notes

To order reprints of this article go to:

http://journals.bmj.com/cgi/reprintform

To subscribe to Occupational and Environmental Medicine go to:

http://journals.bmj.com/subscriptions/ 


\section{Reducing sickness absence in occupational settings}

\section{Jussi Vahtera, ${ }^{1}$ Mika Kivimäki ${ }^{1,2}$}

Sickness absence is known to be an important cause of lost productivity. In the United States, for example, the total days lost due to sickness absence are estimated to represent $3-7 \%$ of all regularly scheduled work days. ${ }^{1}$ Sickness absence is also a measure of the use of health services and increasingly is considered a measure of health. Obviously, some sick leave represents voluntary absenteeism not related to physical or mental illness, and some employees work while ill and record no absences. However, this subjective component is an unlikely source of major bias in longer sick leaves requiring physician examination. Records of such absences have been found to be a more powerful predictor of all-cause mortality than established self-reported health measures and various objective measures of specific physical illnesses and medical conditions. They are also a strong predictor of specific causes of death, such as cardiovascular disease, cancer, alcohol-related causes and suicide, and future disability retirement. ${ }^{23}$ Furthermore, among employees reporting poor health, low medically certified sickness absences have been found to be associated with subsequent improvement in health status. ${ }^{4}$

Given that sickness absence represents a major public health burden on employees, employers, the health care system and society as a whole, surprisingly little is known concerning the optimal occupational health intervention strategies for employees with a high risk of sickness absence. A number of published studies have focussed on methods of reducing sickness absence, but they are typically based on non-randomised study designs. ${ }^{5}$ Such data may be misleading due to selection bias and confounding. A wellknown illustration of these problems relates to antioxidant vitamins. These vitamins have been associated with a

\footnotetext{
${ }^{1}$ Finnish Institute of Occupational Health, Helsinki, Finland; ${ }^{2}$ Department of Epidemiology and Public Health, University College London, London, UK

Correspondence to: Professor Jussi Vahtera, Unit of Excellence in Psychosocial Factors, Finnish Institute of Occupational Health, Lemminkäisenkatu 14-18B, FI20520 Turku, Finland; jussi.vahtera@ttl.fi
}

reduced risk of cardiovascular disease, cancer and all-cause mortality in several observational studies but have failed to show any protection against these disorders in well conducted randomised controlled trials (RCTs). ${ }^{6}$

Until now, only two RCTs aimed at reducing sickness absence within a highrisk group have been published. A Norwegian trial examined whether minimal postal intervention had any effect on the length of sick leave. ${ }^{7}$ The authors randomised consecutive newly sick-listed employees with musculoskeletal or mental disorders to intervention and control groups. Within the intervention group, sick-listed persons received a general information letter and a questionnaire when they had been absent for more than 14 days. The intervention did not show efficacy in reducing the mean length of sickness absence in the intervention group compared to controls in general, although a reduction was observed in subgroups with mental disorders, rheumatic disorders and arthritis. A Dutch trial evaluated the effectiveness of an occupational health intervention programme for workers at risk for early retirement. ${ }^{8}$ The participants were over 50 years of age and indicated that they would not be able to work up to their retirement. The intervention programme lasted 6 months, was conducted by an occupational physician, and comprised at least three consultations. Fewer employees retired early in the intervention group than in the control group, and the total average number of sick leave days in 2 years was lower in the intervention group than in the control group. However, 2 years after the randomised intervention, no differences between the two groups were found.

In this issue of Occupational and Environmental Medicine, the report by Taimela et al (see pages 236 and 242) makes an important contribution to the literature. ${ }^{9}$ This RCT evaluated the effectiveness of an occupational health intervention for employees at risk of sickness absence in 48 occupational health centres in Finland. Subjects with a high or intermediate risk of sickness absence were detected by a questionnaire survey which distinguished those with self-assessed problems with working ability, pain, impairment due to musculoskeletal problems, sleeping problems, fatigue and depression from all other employees. The intervention in the high-risk group consisted of personal feedback from the health survey and an invitation to a consultation with occupational health services in order to construct an action plan and, if appropriate, referral to a further consultation by a specialist or psychologist. The intervention in the intermediate risk group was an invitation to call a phone advice centre. The employees in the control groups received care as usual. They could consult their occupational nurse or physician on request, but they were not invited for a consultation and did not receive feedback of their results. The primary outcome was sickness absence during a 12-month followup.

Taimela et al found a marked difference in the number of sickness absence days between the intervention arm and the usual care treatment arm. A combination of personal feedback, invitation to a consultation at occupational health services and possible referral to a further consultation was related to 11 absence days less per employee per year, a figure which is obviously of economic importance. ${ }^{9}$ Although the invitation to call a phone advice centre alone showed no effect, this study is important in at least three ways: first, it adds to the scarce body of RCTs on sickness absence reduction; second, it provides evidence that reduction in sickness absence in a highrisk group is possible in occupational settings and with a pragmatic approach; and third, it shows that a questionnaire survey, a simple and cheap way of collecting information, is feasible for identifying a group of employees at high risk of work disability and sickness absence.

However, many questions remain unanswered as the data came from one Finnish corporation, the majority of employees being male blue-collar workers with a relatively low response rate. Thus, we do not know whether the same intervention would be effective in other branches of industry, in other types of populations or in countries with different health care systems. It has been claimed that randomised intervention studies are not feasible in real-life occupational settings. Hopefully, this study will refute such claims, stimulate more high quality research on employees at high risk of 
sickness absence and also encourage employers and occupational health professionals to move from non-targeted health checks towards targeted preventive measures to sustain work ability.

\section{Competing interests: None.}

Occup Environ Med 2008;65:219-220. doi:10.1136/oem.2007.036061

\section{REFERENCES}

1. Johns G. How often were you absent? A review of the use of self-reported absence data. J Appl Psychol 1994;79:574-91.
2. Kivimaki M, Head J, Ferrie JE, et al. Sickness absence as a global measure of health: evidence from all-cause mortality in the Whitehall II study. BMJ 2003;327:3649.

3. Vahtera J, Pentti J, Kivimäki M. Sickness absence as a predictor of mortality among male and female employees. J Epidemiol Community Health 2004;58:321-6.

4. Kivimäki M, Ferrie JE, Shipley MJ, et al. Low medically-certified sickness absence among employees with poor health status predicts future health improvement: the Whitehall II study. Occup Environ Med (in press)

5. Michie S, Williams S. Reducing work related psychological ill health and sickness absence: a systematic literature review. Occup Environ Med 2003;60:3-9
6. Lawlor DA, Davey Smith G, Kundu D, et al. Those confounded vitamins: what can we learn from the differences between observational versus randomised trial evidence? Lancet 2004;363:1724-7.

7. Fleten N, Johnsen R. Reducing sick leave by minimal postal intervention: a randomised, controlled intervention study. Occup Environ Med 2006;63:67682.

8. de Boer AG, van Beek JC, Durinck J, et al. An occupational health intervention programme for workers at risk for early retirement; a randomised controlled trial. Occup Environ Med 2004:61:924-9.

9. Taimela S, Malmivaara A, Justén $S$, et al. The effectiveness of two occupational health intervention programs in reducing sickness absence among employees at risk. Two randomized controlled studies. Occup Environ Med 2007;64:236-41.

\section{Committee on Publication Ethics (COPE) - Seminar 2008}

\subsection{0am-4.30pm Friday 4 April 2008, Woburn House, London, UK}

This year's seminar will focus on three key topics: (1) How does patient privacy legislation affect an editor's ability to publish? (2) What is publication? - the changing definitions of publication. (3) COPE's new Best Practice Guidelines. There will also be a short demonstration of an anti-plagiarism system as it is working in a publishing house.

Invited speakers will discuss legislation on privacy and data protection that editors need to be aware of; how editors should respond to more and more data being available online prior to formal peer-reviewed publication; and what happens to a publication after it appears in print.

The newly designed COPE website will be demonstrated, and there will be interactive workshops on common ethical and editorial dilemmas.

Editors, authors and all those interested in improving the standard of publication ethics are welcome.

The seminar will include invited talks:

- A Pandora's box of tissues-legislation in relation to tissues and cells

- The promise and perils of patient privacy

- Pre-publication or duplicate publication? How to decide

- What really happens to a publication after it appears in print

- Screening for plagiarism: the CrossCheck initiative

In addition:

- Discussion of COPE's new Best Practice Guidelines with experiences from journals who have piloted the audit

- COPE's new website unveiled

- Interactive workshops on the key topics of the seminar.

- Opportunities to network with other editors and share your experiences and challenges

The seminar is free for COPE members and $\mathbf{f 5 0 . 0 0}$ for non-members. Numbers are limited and early booking is advisable. For registration or more information please contact the COPE Administrator at cope@bmjgroup.com or call 020-7383-6602.

For more information on COPE visit www.publicationethics.org.uk/ 